\title{
Rapid Determination of Calcium in Milk and Water Samples by Reflectance Spectroscopy
}

\author{
Hayati Filik, Duygu Aksu, Reşat Apak \\ Department of Chemistry, Faculty of Engineering, Istanbul University, Istanbul, Turkey \\ E-mail: filik@istanbul.edu.tr \\ Received October 23, 2010; revised March 7, 2011; accepted May 16, 2011
}

\begin{abstract}
Reflectance spectroscopy (RS) can be used as a rapid and sensitive method for the quantitative determination of low amounts of calcium. In this analytical technique, the analyte in complex samples is extracted onto a solid sorbent matrix loaded with glyoxal bis (2-hydroxyanil (GBHA) and then quantified directly on the sorbent surface. The measurements were carried out at a wavelength of $566.1 \mathrm{~nm}$ yielding the largest divergence of reflectance spectra before and after reaction with the analyte element. The optimum response was obtained in $0.2 \mathrm{~mol} \cdot \mathrm{L}^{-1} \mathrm{NaOH}$ solution, and the response time of the sensor was about $5 \mathrm{~min}$, depending on the concentration of $\mathrm{Ca}$ (II). The calibration curve of $\mathrm{Ca}$ (II) was found to be linear on semi-logarithmic scale within the concentration range of $0.3-40 \mathrm{mg} \cdot \mathrm{L}^{-1}$, with a LOD of $0.15 \mathrm{mg} \cdot \mathrm{L}^{-1}$ in the low concentration range. The sensor response from different sensors $(n=5)$ gave an R.S.D. of $1.4 \%$ at $10 \mathrm{mg} \cdot \mathrm{L}^{-1} \mathrm{Ca}(\mathrm{II})$. The response characteristics of the sensor including dynamic range, reversibility, reproducibility, response time and lifetime are discussed in detail. The main advantages of this prototype device are sensitivity and higher selectivity over $\mathrm{Mg}(\mathrm{II})$. The proposed method has been successfully applied to the determination of $\mathrm{Ca}$ (II) in milk and drinking water samples.
\end{abstract}

Keywords: Calcium, Reflectance, Optical Sensor, Glyoxal Bis (2-Hydroxyanil)

\section{Introduction}

Calcium is an essential element for humans, and is also responsible for 'water hardness', a water quality parameter frequently tested in industrial plants and municipal water treatment facilities. Calcium is biologically required for numerous functions, such as building and maintaining the bones and teeth, blood clotting, transmitting of the nerve impulses and regulating heart's rhythm [1]. Milk and dairy products are convenient sources of calcium for many people [2]. Drinking water is an important source of calcium in the elderly, particularly because of increased needs and decreased consumption of dairy products [3]. Therefore, low-cost, sensitive and selective methods are necessary to determine this ion.

A traditional method for the quality control of calcium-containing products and hard water is complexometric titration with EDTA using suitable indicators and masking agents. Lower concentrations of $\mathrm{Ca}^{2+}$ in aqueous samples require more sensitive instrumental analytical techniques such as flame atomic absorption spectrometry (FAAS), inductively coupled plasma (ICP) emission spectrometry, capillary electrophoresis, ion chromatography, and spectrophotometry, though the most widely used one is AAS $[1,4]$. The use of different concentrations of ionization buffers (e.g., containing $\mathrm{La}(\mathrm{III})$ ) has been recommended in the FAAS analysis of different classes of substrates [5-11]. Lanthanum salts enhance the atomic absorption signals of $\mathrm{Ca}$, especially in phosphate- containing matrices. The addition of ionization suppressants to both samples and calibration standards can reduce interference effects. Analyses of milk and milk products are routinely performed by a number of dairy laboratories to implement quality control with regard to nutritional components. FAAS analysis of milk products require sample preparation such as dry ashing or wet digestion (for decomposition of a sample into a homogeneous liquid phase). The complexity of Ca matrices (complexed with protein) and its low concentration levels in aqueous solutions, together with possible effects of various matrix constituents, make direct measurement of this metal ion difficult [11]. Therefore, it is of great importance to develop a simple and rapid detection technique for the routine quality con- 
trol, real time monitoring and field measurement of $\mathrm{Ca}(\mathrm{II})$ in milk and drinking water samples.

In recent years, increasing interest has been directed to the development of optical chemical sensors for metal ions. The incorporation of fibre optics in the development of chemical sensors is receiving interest because of the numerous advantages of this approach over traditional sensing methods. The ability to monitor analyte concentrations in real time and real space measurements require rapid methods applicable to many fields, including environmental control, industry, security, and health. Recently, a few reports have appeared on the development of optical sensors for calcium ion sensing. Immobilized arsenazo III [12,13], chlorophosphonazo III [14], and amine-containing calcium green derivative [15] in various matrices were used for molecular spectroscopic calcium sensing based on reflectance [12], absorbance $[13,14]$ and fluorescence [15] mesurements. A number of $\mathrm{Ca}(\mathrm{II})$ membrane sensors based on different ion carriers have also been reported [16-23]. It should also be added that many data on analyte/polymer interactions are based on empirical information, and physico-chemical explanations on interaction mechanisms still remain relatively speculative [23].

In this communication, the performance of immobilized glyoxal bis (2-hydroxyanil) (GBHA) on Amberlite $\mathrm{XAD}-16$ as a reagent phase in the development of an optical reflectance sensor for $\mathrm{Ca}(\mathrm{II})$ determination has been demonstrated. The use of the chelating properties of glyoxal bis (2-hydroxyanil) (GBHA) in a specific spot test for calcium was first reported by Goldstein and Stark-Mayer [24]. GBHA is a highly specific $\mathrm{Ca}(\mathrm{II})$ reagent, widely used to determine calcium concentrations in various samples. The structural formula of GBHA is shown in Figure 1. Since routine quality control of calcium is required for industrial products as well as for milk and drinking water samples, the developed sensor system was applied to the detection and quantitation of calcium in milk and water samples.

In the course of calcium sensing, special care was exercised on the rapid responsiveness, sensitivity, and selectivity of the developed sensor. Although high molecular weight PVC is generally employed as the base polymer for such sensors, the synthesized membranes

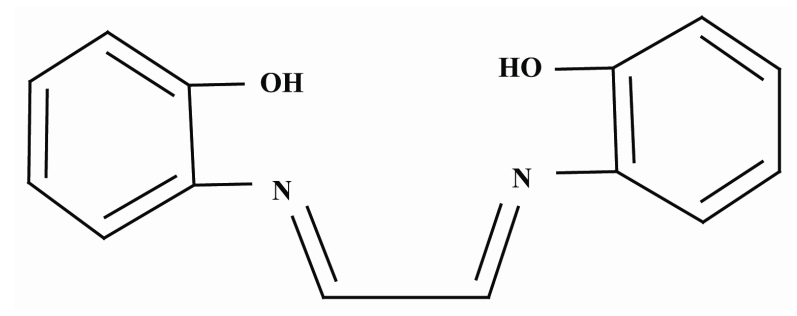

Figure 1. The structural formula of GBHA. may give a retarded response to the analyte, depending on the type and concentration of PVC in the polymer blend, probably due to irreversible fixation of the sensing reagent (unreported preliminary experiments). Potentiometric sensors (ion-selective electrodes) may give responses to ionized and complexed calcium (such as in milk) at different rates [11], decreasing analytical precision. The limit of detection (LOD) values for Ca-sensors synthesized by various research groups such as CapitánVallvey et al. $\left(\mathrm{LOD}=0.2 \mathrm{mg} \cdot \mathrm{L}^{-1}\right)$ [14], Caglar et al. $\left(\mathrm{LOD}=0.88 \mathrm{mg} \cdot \mathrm{L}^{-1}\right)$ [12], and Malcik et al. $(\mathrm{LOD}=3.4$ $\mathrm{mg} \cdot \mathrm{L}^{-1}$ ) [13] were rather high, and remain to be a challenge to be further lowered for applications requiring higher sensitivity. Moreover, in all the mentioned studies, the magnesium tolerance of the sensor was 4- or 5-fold of the amount of calcium being determined [12-14], and an increase in $\mathrm{Ca} / \mathrm{Mg}$ selectivity is required in new sensors. The proposed sensor has been designed to cope with all these inadequacies. This sensor has a selectivity for calcium, as it does not respond to the sister element, magnesium.

\section{Experimental}

\subsection{Apparatus}

Experiments were carried out using a commercially available miniature fibre-optic based spectrometer (Ocean Optics Inc., HR4000CG-UV-NIR) which utilises a small tungsten halogen lamp (Ocean Optics Inc.) as the light source and a CCD based detector for reflectance measurements. Light reflected from the flow cell was transmitted by a bundle of optical fibres to a miniature fibre-optic spectrophotometer (Ocean Optic HR4000CGUV-NIR) which on the other hand was connected to a PC (Dell-compatible) and also a printer. For optical isolation, the flow cell and the detector were kept in a black box to minimise any interference from ambient light. The spectral deconvolution was performed after smoothing the spectra by a 25-point Fourier transform filter using peak fitting module in OriginPro7.0 software (OriginLab Co., USA). Spectral deconvolution using a Gaussian model accurately represents reflectance bands as discrete mathematical distributions and resolves composite reflectance features into individual bands [25], whereas spectral smoothing is performed with the aid of a Fourier transform algorithm. A mechanical shaker (Nüve, Turkey) having speed control facility was used for batch equilibration. A Shimadzu AA-6701-F atomic absorption spectrophotometer was used for calcium determinations. Air-acetylene flame was used for atomization, and calcium was measured at the analytical wavelength of 422.7 $\mathrm{nm}$. 


\subsection{Chemicals and Reagents}

All chemicals used were of analytical-reagent grade, except where otherwise stated; calcium-free distilled water was used throughout for the preparation of all solutions. All metal salts were used without further purification. Polystyrene-divinylbenzene (Amberlite XAD-16) resin was purchased from Sigma (Madrid, Spain). Glyoxal bis (2-hydroxyanil) (GBHA) was obtained from Riedel de-Haën (Seelze, Germany), and used without further purification. Accurately weighed amounts of calcium carbonate, dried at $110^{\circ} \mathrm{C}$ for $1 \mathrm{~h}$, were dissolved in dilute hydrochloric acid, then diluted to the appropriate volume of stock solution. Working solutions were prepared by dilution as required. The stock calcium solution was standardized against ethylenediamine tetraacetate (EDTA) using murexide as metallochromic indicator for compleximetric titration. The stock color reagent was GBHA solution, prepared by dissolving $0.5 \mathrm{~g}$ of the reagent in $100 \mathrm{~mL}$ of ethanol $\left(2 \times 10^{-2} \mathrm{~mol} \cdot \mathrm{L}^{-1}\right)$.

\subsection{Sample Preparation}

Two UHT milk samples and mineral water samples of different commercial brands were supplied at random from the local market in Istanbul, Turkey. All the drinking water bottles were stored under refrigeration at $4^{\circ} \mathrm{C}$, and opened on the day of analysis. The samples were analyzed directly without pretreatment.

Trichloroacetic acid method: A portion (5 mL) of milk sample was mixed with $20 \%$ trichloroacetic acid (TCA) in the volume ratio 1:1. After waiting for $30 \mathrm{~min}$, the solution was centrifuged. The volume of the centrifugate was made up to $100 \mathrm{~mL}$ with water and an aliquot was used for the determination of calcium.

Ashing method: Milk samples $(4 \mathrm{~mL})$ were weighed into a porcelain crucible and dried on a hot plate. After charring, samples were incinerated in a muffle furnace at $500^{\circ} \mathrm{C}$. If necessary, the ash was bleached by treatment with $\mathrm{HNO}_{3}$ and heating in the muffle furnace for $1 \mathrm{~h}$. Finally, the ashes were diluted with concentrated nitric acid $(1 \mathrm{~mL})$ and the mixture was heated to dryness. Then the residue was dissolved in water and transferred into a $50 \mathrm{~mL}$ calibrated flask, and made up to the mark with distilled water.

\subsection{Impregnation Procedure}

Amberlite XAD-16 resin as obtained from the supplier contained organic and inorganic impurities. To remove these contaminants, it was washed successively with ethanol, water, $1.0 \mathrm{~mol} \cdot \mathrm{L}^{-1} \mathrm{NaOH}$, and $1.0 \mathrm{~mol} \cdot \mathrm{L}^{-1} \mathrm{HCl}$ in this order. The XAD-16 beads were then washed with distilled water until neutral. The sensing material (GBHA) was physically immobilized by adsorption onto Amberlite XAD-16 polymer. The resin beads were dried in an oven at $105^{\circ} \mathrm{C}$ for $4 \mathrm{~h}$. A mass of $0.5 \mathrm{~g}$ dry resin (Amberlite XAD-16) beads was treated with $5 \mathrm{ml}$ of 2.0 $\times 10^{-2} \mathrm{~mol} \cdot \mathrm{L}^{-1} \mathrm{GBHA}$ and $5 \mathrm{ml}$ ethanol, and the mixture was shaken at room temperature for $30 \mathrm{~min}$. The resulting white resin beads (loaded with ligand) were filtered off from the supernatant solution, and washed with distilled water to remove the excess of GBHA. Then the resin beads were transfered onto a dry filter paper and pressed for easy drying. Finally, the white resin beads were kept under nitrogen atmosphere when not in use.

\subsection{Sensor Fabrication}

The sensor design was similar to that described by Ahmad and Narayanaswamy and Filik et al. [26-29]. The probe was built using disposable syringe tubes (Tyco Healthcare Group LP, Büyükçekmece, Istanbul, Turkey). A syringe column (5 milliliter plastic syringe, with graduations in milliliters and fifths of milliliters), with a nylon membrane and a stopcock, has been used for preconcentration of $\mathrm{Ca}$ (II). A syringe tube was filled to the $0.5 \mathrm{ml}$ (i.e. 5 $\mathrm{mm}$ ) mark line with the sensing layer (XAD-16-GBHA). The filling mass of the Amberlite XAD-16- GBHA resin was $299.3 \pm 0.5 \mathrm{mg}(\mathrm{n}=5)$. During measurements, the arbitrary unit and the detector were kept in a black box to minimise any interference from ambient light.

\subsection{Recommended Procedure}

A $3 \mathrm{~mL}$ aliquot of the sample solution containing calcium (within the working range of $0.3-40 \mathrm{mg} \cdot \mathrm{L}^{-1}$ ) was placed in a sensor system. Then, $1.0 \mathrm{~mL}$ of $1.0 \mathrm{~mol} \cdot \mathrm{L}^{-1}$ $\mathrm{NaOH}$ was added, and mixed well. The reflectance measurement was carried out by recording the optical signal 5 min after placement of the bifurcated optical fibre in the analyte solution. Reflectance spectra were recorded after 5 min (for full colour development). The measurements were expressed in the units of relative reflectance, which is defined as the difference between the reflectance of the Ca-GBHA/XAD complex $\left(\mathrm{R}_{c}\right)$ and that of the immobilized reagent (GBHA/XAD) alone $\left(\mathrm{R}_{\mathrm{f}}\right)$, both recorded at the same wavelength $(566.1 \mathrm{~nm})$. The blank value was obtained by the same procedure with the exception of $\mathrm{Ca}$ addition.

\section{Results and Discussion}

\subsection{Reflectance Spectra}

Figure 2 shows the reflectance spectra of immobilized 


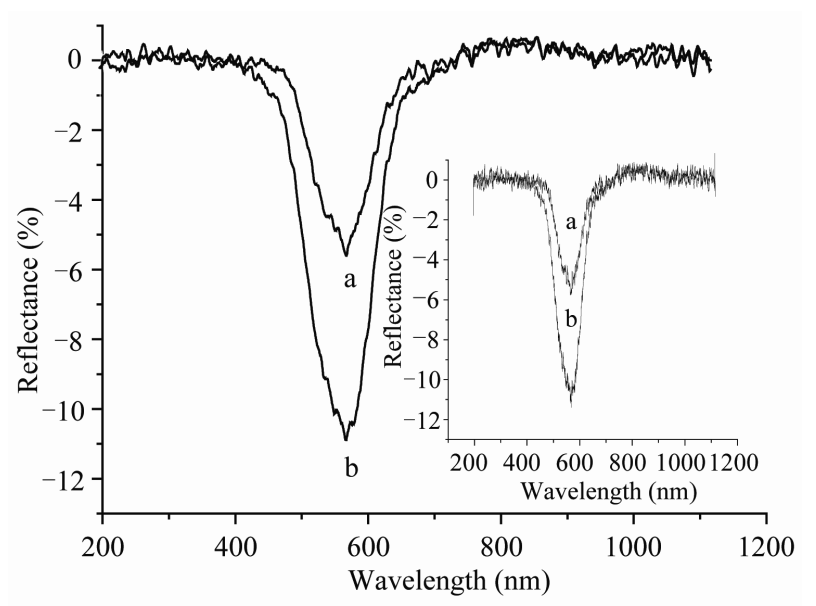

Figure 2. Smoothed reflectance (\%) spectra of immobilized GBHA after reaction with $0.4 \mathrm{mg} \cdot \mathrm{L}^{-1}$ (a) and $1.0 \mathrm{mg} \cdot \mathrm{L}^{-1} \mathrm{Ca}$ (b). Inset shows original reflectance spectra.

GBHA after reaction with varying concentrations of $\mathrm{Ca}(\mathrm{II})$. This caused an increase in the reflectance intensity due to the change in colour of the reagent phase from white to red after reaction with $\mathrm{Ca}(\mathrm{II})$ ions. GBHA is a quadridentate ligand and its chelate with calcium is a $1: 1$ chelate which is unstable. Maximum absorbance of CaGBHA complex was at $530 \mathrm{~nm}$ in solution and maximum reflectance of Ca-GBHA/XAD at $566.1 \mathrm{~nm}$ on the resin phase. Thus, the reflectance measurements were carried out at $566.1 \mathrm{~nm}$.

\subsection{Effect of $\mathrm{NaOH}$ Concentration}

The complex forming reaction between $\mathrm{Ca}$ and GBHA was $\mathrm{pH}$-dependent. The $\mathrm{pH}$ was the first parameter examined for its effect on the response of calcium ion. As found earlier, a high $\mathrm{pH}$ favoured the formation of $\mathrm{Ca}$ GBHA complex. The effect of sodium hydroxide $(\mathrm{NaOH})$ concentration on the formation of maximum colour intensity and stability of the Ca-GBHA was studied. The colour of the immobilized GBHA changed from white to red. As can be seen in Figure 3, considerable reflectance signal intensity was obtained with a concentration of $\mathrm{NaOH}$ ranging from 0.02 to $0.5 \mathrm{~mol} \cdot \mathrm{L}^{-1}$. At a $\mathrm{NaOH}$ concentration higher than $0.2 \mathrm{~mol} \cdot \mathrm{L}^{-1}$, the reflectance signal decreased. It was reported earlier in spectrophotometric measurements that the colour due to Ca-GBHA complex slowly faded in solutions of high $\mathrm{pH}$. Thus, an optimal concentration of $0.2 \mathrm{~mol} \cdot \mathrm{L}^{-1} \mathrm{NaOH}(2.0 \mathrm{~mL}$ of $1.0 \mathrm{~mol} \mathrm{~L}^{-1} \cdot \mathrm{NaOH}$ ) was used in this work. In more acidic and more alkaline solutions, reflectance intensity decreased because of incomplete complex formation and hydrolysis of the complex, respectively. Since magnesium exhibiting similar chemical reactions existed along with calcium in many complex matrices (such as hard water),

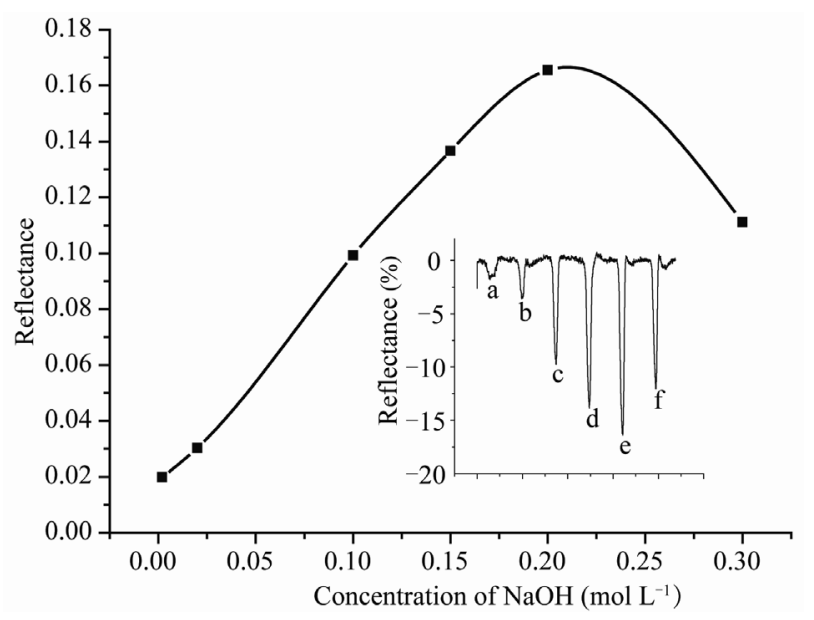

Figure 3. Influence of $\mathrm{NaOH}$ concentration on the sensor response. [Ca(II)]: $10 \mathrm{mg} \cdot \mathrm{L}^{-1}$. The inset shows the intensity profile of the original reflectance spectra. a. 0.001 , b. 0.01 , c. 0.10, d. 0.15, e. 0.20 and f. $0.30 \mathrm{~mol} \cdot \mathrm{L}^{-1} \mathrm{NaOH}$.

the response to $\mathrm{Mg}$ was also investigated. There was no sensor response for $100 \mathrm{mg} \cdot \mathrm{L}^{-1} \mathrm{Mg}$ in the studied $\mathrm{pH}$ range. The reflectance intensity of $\mathrm{Mg}$ was nearly zero in $0.2 \mathrm{~mol} \cdot \mathrm{L}^{-1} \mathrm{NaOH}$ solution.

\subsection{Effect of Amount of GBHA}

The effect of the optimum reagent amount on the response of the corresponding sensor was studied batchwise at room temperature by using different amounts of GBHA in the range $0.02-0.16$ mmol GBHA during its immobilisation on $0.5 \mathrm{~g}$ of XAD-16 resin. The immobilized reagent was later used for reaction with calcium at $10 \mathrm{mg} \cdot \mathrm{L}^{-1}$ concentration. Figure 4 shows that the higher the reagent amount used for immobilisation, the higher was the reflectance signal obtained for the same concentration of calcium. The reflectance intensity increased

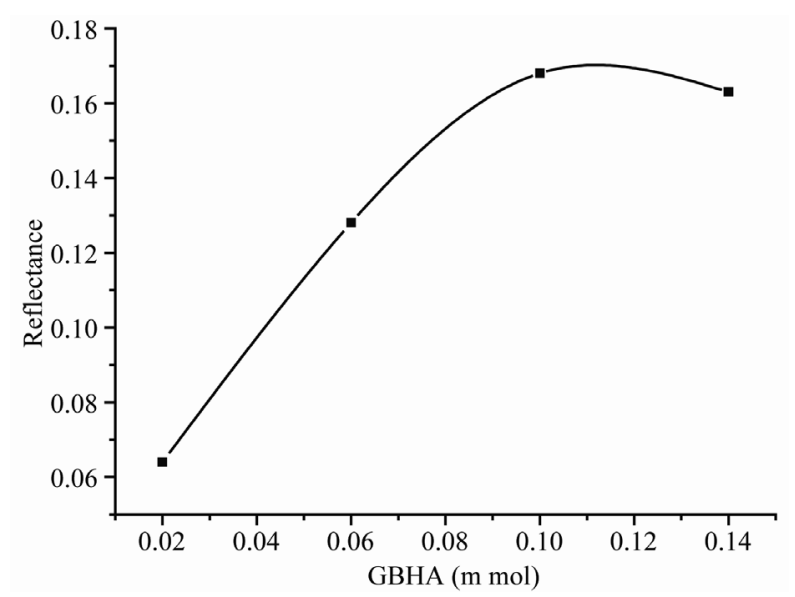

Figure 4. Influence of amount of GBHA on the sensor response; Ca(II): $\mathrm{mg}^{-1} \mathrm{~L}^{-1}$. 
with increasing amount of GBHA up to $0.1 \mathrm{mmol}$, and remained constant between 0.1 and $0.16 \mathrm{mmol}$. Thus, 0.1 mmol of GBHA was selected to ensure a sufficient excess of the reagent throughout the experiment work.

\subsection{Effect of Shaking Time on the Sorption of GBHA}

The influence of time of immobilization on the optical properties of the sensor is important because of subsequent effects on the response time and dynamic working range of the sensor. This study was carried out at fixed amount of $0.1 \mathrm{mmol}$ of GBHA. The resin beads were inserted into solutions for different time periods ranging between 5 and 60 min. Unbound GBHA was decanted, and loaded support washed with distilled water. After washing, the sensing layers were dried between two filter papers at $25^{\circ} \mathrm{C}$ for $5 \mathrm{~min}$. Then the resin beads were inserted into $10 \mathrm{mg} \cdot \mathrm{L}^{-1} \mathrm{Ca}$ solutions at $\mathrm{pH} 13 \pm 0.2$, and the reflectance of the sensing layers was measured at $566.1 \mathrm{~nm}$. The best reflectance signal was achieved for an immobilization period of $30 \mathrm{~min}$.

\subsection{Interferences}

The effects of representatives of potential interfering species were tested separately. Thus, nitrate and sulfate could be tolerated up to at least $1000 \mu \mathrm{g} \mathrm{L}^{-1}$. On the other hand, the GBHA reagent reacted with only a few metal ions such as $\mathrm{Co}, \mathrm{Ni}, \mathrm{Fe}, \mathrm{Zn}, \mathrm{Cu}, \mathrm{Cd}, \mathrm{Fe}$ and $\mathrm{Mn}$, and also with $\mathrm{Sr}$ and $\mathrm{Ba}$ in alkaline solution. These ions showed no interference on the determination of $\mathrm{Ca}$, even in 1.0 fold excess. High concentrations of these cations can interfere with the calcium response. The responses were influenced by the presence of these ions, because they are complexed with GBHA reagent at the working $\mathrm{pH}$ value. Larger quantities of divalent metals can be eliminated by masking with $\mathrm{KCN}$ ( $2 \mathrm{~mL}$ of $0.1 \%$ ). This reagent forms a stable complex with divalent metals, but does not interfere with the reaction between $\mathrm{Ca}(\mathrm{II})$ and the chelating agent. To perform this study, the interfering cations were studied at a metal-to-interferent ratio of $1: 100$. It was proved that $\mathrm{Ca}(\mathrm{II})$ recoveries were almost quantitative in the presence of KCN, and the complexed ions were completely eliminated. However, in drinking water and milk samples, concentrations of trace metals were generally very low. Accordingly, the addition of $\mathrm{KCN}$ to the medium is not needed. In various samples assayed with a sensor [12-14], Mg(II) at concentrations exceeding 4- to 5-fold was reported to interfere with the determination of calcium. On the other hand, with the proposed technique, $\mathrm{Mg}(\mathrm{II})$ was shown not to interfere even at 100-fold (by wt.) ratios in excess of Ca(II). Thus, the proposed sensor system can be used to determine calcium in drinking water and milk samples without preliminary operations of separation or masking.

\subsection{Response Time}

The sensing time of the probe is a very important parameter for rapid measurement. Figure 5 shows reflectance response of the sensing probe at $566.1 \mathrm{~nm}$ as a function of time when the sensing layer was exposed to 1.0 and $10.0 \mathrm{mg} \cdot \mathrm{L}^{-1} \mathrm{Ca}(\mathrm{II})$. In general, it was observed that the reflectance intensity increased with increasing reaction time. The reflectance of sensor remained constant after a measurement time of $5 \mathrm{~min}$. However, a 7-min system response time was chosen in this study since it yielded a more stable response for a wider $\mathrm{Ca}(\mathrm{II})$ concentration range.

\subsection{Stability of the Sensor and Life Time}

The stability of the sensor was tested by using $10 \mathrm{mg} \cdot \mathrm{L}^{-1}$ $\mathrm{Ca}$ (II) solution. The leaching of the immobilized reagent was evaluated by monitoring the sensor response continuously for $3 \mathrm{~h}$ when the prepared sensor was immersed into $0.2 \mathrm{~mol} \cdot \mathrm{L}^{-1} \mathrm{NaOH}$ solution. The experiment indicated that for this duration of time, the signal response was quite stable with a relative standard deviation (RSD) of $3.4 \%$. Because of the unstable nature of the reagent, it is also recommended that it be kept under a nitrogen atmosphere and all the sensing layers were sheltered from ambient light. A study on stability of the sensor was carried out to detect the possibility of decomposition of the reagent phase when it was kept under nitrogen atmosfere. The proposed sensing layer was stable and could be used for at least 3 weeks without observing any change

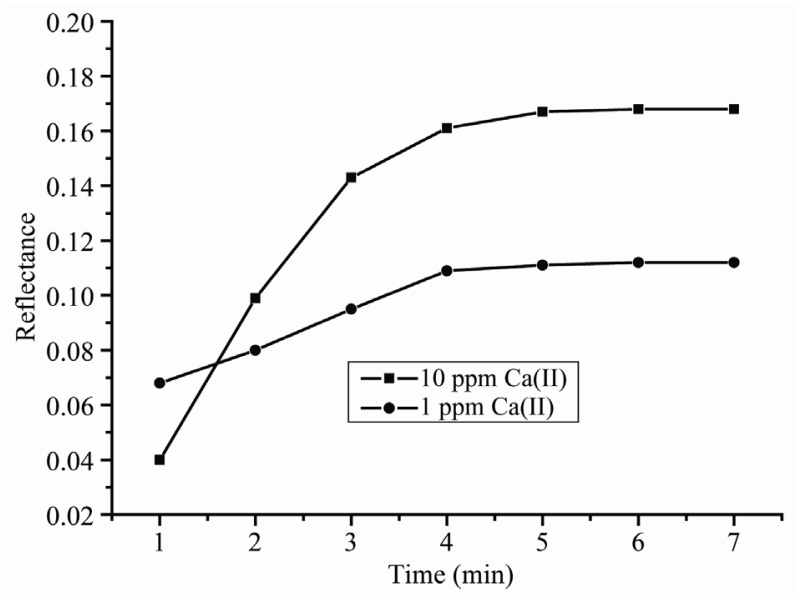

Figure 5. Typical response curve of the Amberlite XAD-16/ GBHA-Ca at $566.1 \mathrm{~nm}$ as a function of time when sensor was exposed to 1.0 and $10.0 \mathrm{mg} \cdot \mathrm{L}^{-1} \mathrm{Ca}$ ion. 
in its response signal characteristics. In this test, it was demonstrated that the reagent phase was stable and no decomposition occurred.

\subsection{Analytical Characteristic of the Sensor}

The proposed methodology was able to produce analytical fits with good linearity in the range $0.3-1.0 \mathrm{mg} \cdot \mathrm{L}^{-1}$. As concentration increased beyond a limiting level, the sensor produced a semi-logarithmic response against $\mathrm{Ca}(\mathrm{II})$ concentrations lying in the range $0.3-40 \mathrm{mg} \cdot \mathrm{L}^{-1}$. This phenomenon can be interpreted accordingly by Oehme and Wolfbeis explanations [30]. When a metal ion reacts with an indicator at a molar ratio of $1: 1$, and neglecting the activity coefficients, the conditional stability constant can be defined as: $\mathrm{K}_{\mathrm{s}}=[\mathrm{MeI}] /[\mathrm{Me}][\mathrm{I}]$, where [I] denotes the concentration of the indicator which is not bound in the complex [MeI], and [Me] the concentration of the metal ion that is not bound to the ligand. It is assumed that activity effects in the immobilized phase are equivalent for I and MeI species and thus may be considered to cancel. As pointed out above, it is the concentration of the dye-metal complex (i.e., [MeI]) or the unbound indicator [I] which is measured, and [MeI] and [I] vary with analyte ([Me]) concentration as follows [30]:

$$
\begin{aligned}
& {[\mathrm{MeI}] }=\left\{\mathrm{K}_{\mathrm{s}}[\mathrm{Me}] /\left(1+\mathrm{K}_{\mathrm{s}}[\mathrm{Me}]\right)\right\} \mathrm{c}_{\mathrm{i}} \\
&=\left\{[\mathrm{Me}] / \mathrm{K}_{\mathrm{s}}^{-1}+[\mathrm{Me}]\right\} \mathrm{c}_{\mathrm{i}} \\
& {[\mathrm{I}]=\left\{1 /\left(1+\mathrm{K}_{\mathrm{s}}[\mathrm{Me}]\right)\right\} \mathrm{c}_{\mathrm{i}} }
\end{aligned}
$$

where $c_{i}$ is the total concentration of free and combined indicator molecules. Therefore, at low concentration of analyte (i.e. where $[\mathrm{Me}] \ll 1 / \mathrm{K}_{\mathrm{s}}$ ), response is approximately proportional to analyte concentration [Me]. As concentration increases, response becomes curved, reaching a limiting value when $[\mathrm{Me}] \gg 1 / \mathrm{K}_{\mathrm{s}}$. This corresponds to saturation of the sensing reagent with analyte. A number of several recent studies have also used logarithm of analyte concentration in constructing calibration curves [31-33]. By extending the linear range using a semi-logarithmic scale (Figure 6), a whole range of concentrations between 0.3 and 40 ppm could be accurately measured. The reproducibility of the sensor was checked by five replicate determinations $(\mathrm{N}=5)$ at 10 $\mathrm{mg} \cdot \mathrm{L}^{-1}$ level of $\mathrm{Ca}(\mathrm{II})$. The reflectance measurements were highly reproducible; the relative standard deviation (RSD) for $10 \mathrm{ppm} \mathrm{Ca(II)} \mathrm{solution} \mathrm{was} 1.4 \%$. The limit of detection (LOD) of $\mathrm{Ca}(\mathrm{II})$, defined as the concentration equivalent to a signal of blank plus three times the standard deviation of the blank, was calculated to be 0.15 $\mathrm{mg} \cdot \mathrm{L}^{-1}$ in the low concentration range of linearity. The sensitivity of the proposed method in terms of lowering the LOD of Ca-sensing was better than those of recent

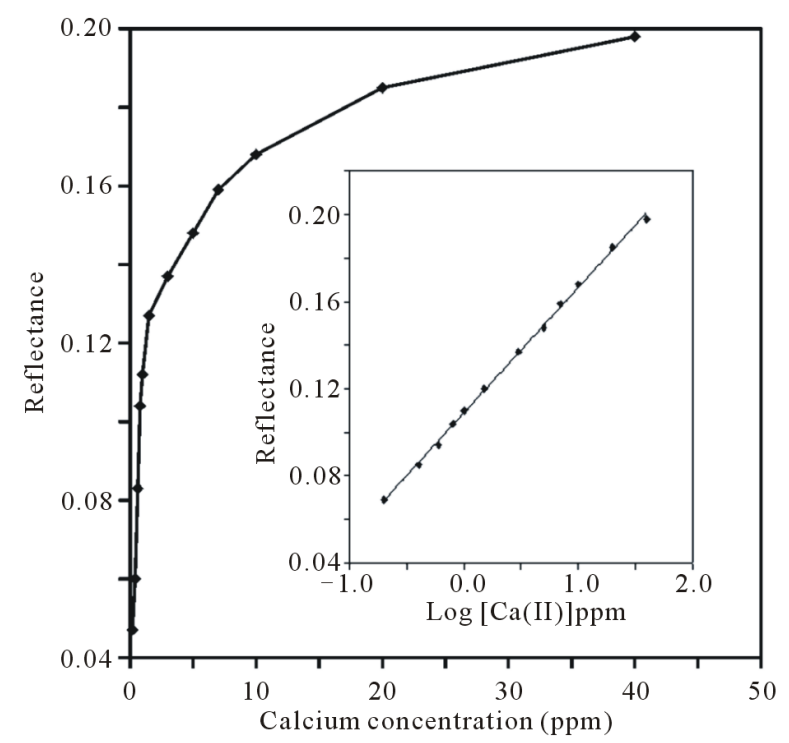

Figure 6. Response to different calcium concentrations. The inset shows the calibration curve of $\mathrm{Ca}$ (II) immobilized on GBHA/XAD-16.

analog sensors manufactured by Caglar et al. [12] and Malcik et al. [13]. The proposed sensing method was validated against flame-AAS analysis of known complex samples of Ca.

\subsection{Reversibility}

The sensor material placed into a column could be regenerated with an acid eluent. The regeneration process of the sensor was checked by washing the used sensing layer with different concentrations $(0.01,0.1$ and 0.2 $\mathrm{mol} \cdot \mathrm{L}^{-1}$ ) of $\mathrm{HCl}$. At all three $\mathrm{HCl}$ concentrations tested, complete regeneration of the sensing layer was obtained at time intervals of $10 \mathrm{~min}, 5 \mathrm{~min}$ and $1 \mathrm{~min}$, respectively. However, the sensing layer after two successive regenerations was completely decomposed. Therefore, the use of a fresh sensing layer is recommended for each measurement.

\subsection{Applications}

To check the validity of the proposed method, several milk and drinking water samples were analysed for Ca. The calcium contents of several samples of drinking water and milk were determined by the Ca-sensor, and the results compared with those obtained using AAS. The results for three types of milk and drinking water are shown in Tables 1 and 2. There was excellent agreement between the results obtained with the proposed sensor and AAS in regard to both analytical accuracy and precision. Since Ca is not susceptible to volatilization losses during a pretreatment scheme of charring-wet ashingfurnace heating, a complex sample such as milk gave 
Table 1. Analysis of three drinking water samples by using FAAS and the proposed sensor $(n=3)$.

\begin{tabular}{cccc}
\hline Water Samples & $\begin{array}{c}\text { Declared } \\
\left(\mathrm{mg} \cdot \mathrm{L}^{-1}\right)\end{array}$ & $\begin{array}{c}\text { FAAS } \\
\left(\mathrm{mg} \cdot \mathrm{L}^{-1}\right)\end{array}$ & $\begin{array}{c}\text { Found }^{\mathrm{a}} \\
\left(\mathrm{mg} \cdot \mathrm{L}^{-1}\right)\end{array}$ \\
\hline Pinar & 6.0 & $6.1 \pm 0.3$ & $5.94 \pm 0.6$ \\
Hayat & 19.7 & $19.7 \pm 0.2$ & $19.9 \pm 0.2$ \\
Erikli & 4.0 & $4.0 \pm 0.1$ & $3.96 \pm 0.3$ \\
\hline
\end{tabular}

${ }^{\mathrm{a}}$ The proposed method

Table 2. Analysis of three milk samples by using FAAS and the proposed sensor $(n=3)$.

\begin{tabular}{lccc}
\hline $\begin{array}{l}\text { Milk } \\
\text { Samples }\end{array}$ & Declared $\left(\mathrm{mg} \cdot \mathrm{L}^{-1}\right)$ & FAAS $\left(\mathrm{mg} \cdot \mathrm{L}^{-1}\right)$ & Found $^{\mathrm{a}}\left(\mathrm{mg} \cdot \mathrm{L}^{-1}\right)$ \\
\hline Danone & 1008 & $1010 \pm 1$ & $1015 \pm 3$ \\
İçim & 1120 & $1125 \pm 2$ & $1130 \pm 4$ \\
Pınar & 1200 & $1202 \pm 2$ & $1208 \pm 5$ \\
\hline
\end{tabular}

${ }^{\mathrm{a}}$ The proposed method.

correct Ca findings with the proposed method.

\section{Conclusions}

The advantage of employing a GBHA-based sensor over the conventional methods for $\mathrm{Ca}$ (II) determination lies in the ease of its detection, use of less amount of chemicals, and less time consumption. In the standard colorimetric determination, the precipitated $\mathrm{Ca}(\mathrm{II})$-GBHA complex must be extracted into an organic solvent, and this introduces complexity in laboratory procedures as well as in difficult disposition of used solvents. The results of this study have shown that the proposed sensor is applicable to the determination of calcium in drinking water and milk samples. The application of the procedure can be extended to the determination of calcium in different samples having very low metal contents. There is definite selectivity for Ca over Mg. The method for drinking water and milk is simple, fast and highly reproducible.

\section{Acknowledgements}

The authors gratefully acknowledge the Scientific and Technological Research Council of Turkey (TÜBITTAK) (Grant no: 109T856) for financial support.

\section{References}

[1] V. Vičkačkaitè, S. Tautkus and R. Kazlauskas, "Determination of Calcium in Mineral Waters by Flame Atomic Absorption Spectrometry,” Chemija, Vol. 18, No. 4, 2007, pp. 34-37.

[2] A. J. Lanou, S. E. Berkow and N. D. Barnard, "Calcium,
Dairy Products, and Bone Health in Children and Young Adults: A Reevaluation of the Evidence,” Pediatrics, Vol. 115, No. 3, 2005, pp. 736-743. doi:10.1542/peds.2004-0548

[3] S. Marque, H. Jacqmin-Gadda, J. -F. Dartigues and D. Commenges, "Cardiovascular Mortality and Calcium and Magnesium in Drinking Water: An Ecological Study in Elderly People,” European Journal of Epidemiology, Vol. 18, No. 4, 2003, pp. 305-309. doi:10.1023/A:1023618728056

[4] K. Grudpan, J. Jakmunee, Y. Vaneesorn, S. Watanesk, U Aye Maung and P. Sooksamiti, "Flow Injection Spectrophotometric Determination of Calcium Using Murexide as a Color Agent,” Talanta, Vol. 46, No. 6, 1998, pp. 1245-1247. doi:10.1016/S0039-9140(97)00410-4

[5] A. Moreno-Cid, M. C. Yebra, "Continuous UltrasoundAssisted Extraction Coupled to a Flow Injection-Flame Atomic Absorption Spectrometric System for Calcium Determination in Seafood Samples," Analytical and Bioanalytical Chemistry, Vol. 379, No. 1, 2005, pp. 77-82. doi:10.1007/s00216-003-2452-6

[6] B. Welz, “Atomic Absorption Spectrometry,” Vancouver Coastal Health, Weinheim, 1985.

[7] R. Kataky, D. Parker and A. Teasdale, "Comparative Study of Tripodal Oxa-Amides and Oxaesters as Ionophores in Potentiometric Ion-Selective Electrodes for Alkali and Alkaline Earth Cations,” Analytica Chimica Acta, Vol. 276, No. 2, 1993, pp. 353-360. doi:10.1016/0003-2670(93)80404-9

[8] M. W. Welch, D. W. Hamar, M. J. Fettman, "Method Comparison for Calcium Determination by Flame Atomic Absorption Spectrophotometry in the Presence of Phosphate," Clinical Chemistry, Vol. 36, No. 2, 1990, pp. 351-354.

[9] Z. Arslan, J. F. Tyson, "Determination of Calcium, Magnesium and Strontium in Soils by Flow Injection Flame Atomic Absorption Spectrometry,” Talanta, Vol. 50, No. 5, 1999, pp. 929-937. doi:10.1016/S0039-9140(99)00187-3

[10] A. P. Udoh, “Atomic Absorption Spectrometric Determination of Calcium and other Metallic Elements in Some Animal Protein Sources,” Talanta, Vol. 52, No. 6, 2000, pp. 749-754. doi:10.1016/S0039-9140(00)00368-4

[11] T. J. Cardwell, R. W. Cattrall, G. J. Cross, R. I. Mrzljak and G. R. Scollary, "Determination of Calcium in Waters, Milk and Wine by Discontinuous-Flow Analysis," Analyst, Vol. 115, No. 10, 1990, pp. 1235-1237. doi:10.1039/an9901501235

[12] P. Caglar, S. A. Tuncel, N. Malcik and J. P. Landers, “A Microchip Sensor for Calcium Determination,” Analytical and Bioanalytical Chemistry, Vol. 386, No. 5, 2006, pp. 1303-1312.

[13] N. Malcik, J. P. Ferrance, J. P. Landers and P. Caglar, "The Performance of a Microchipbased Fiber Optic Detection Technique for the Determination of $\mathrm{Ca}^{2+}$ ions in Urine,” Sensors Actuators B, Vol. 107, No. 1, 2005, pp. 24-31. doi:10.1007/s00216-006-0776-8

[14] L. F. Capitán-Vallvey, P. A. de Cienfuegos-Gálvez, M. D. 
F. Ramos and R. Avidad-Castañeda, "Determination of Calcium by a Single-Use Optical Sensor," Sensors Actuators B, Vol. 71, No. 1-2, 2000, pp. 140-146. doi:10.1016/S0925-4005(00)00602-X

[15] M. Shortreed, R. Kopelman, M. Kuhn, B. Hoyland, "Fluorescent Fiber-Optic Calcium Sensor for Physiological Measurements,” Analytical Chemistry, Vol. 68, No. 8, 1996, pp. 1414-1418. doi:10.1021/ac950944k

[16] U. Schaller, E. Bakker and E. Pretsch, “Carrier Mechanism of Acidic Ionophores in Solvent Polymeric Membrane Ion-Selective Electrodes," Analytical Chemistry, Vol. 67, No. 18, 1995, pp. 3123-3132. doi:10.1021/ac00114a005

[17] U. Schaller, E. Bakker, U. E. Spichiger and E. Pretsch, "Ionic Additives for Ion-Selective Electrodes Based on Electrically Charged Carriers,” Analytical Chemistry, Vol. 66, 1994, pp. 391-398. doi:10.1021/ac00075a013

[18] A. Kumar, S. K. Mittal, "PVC Based Dibenzo-18Crown-6 Electrode for Ca(II) Ions," Sensors Actuators B, Vol. 99, No. 2-3, 2004, pp. 340-346.

[19] A. El-Jammal, A. A. Bouklouze, G. J. Patriarche and G. D. Christian, "Use of Ethylene-Vinylacetate as a New Membrane Matrix for Calcium Ion-Selective Electrode Preparation," Talanta, Vol. 38, No. 8, 1991, pp. 929-935. doi:10.1016/0039-9140(91)80274-4

[20] T. Dimitrakopoulos, J. R. Farrell and P. J. Iles, "PhotoCured Calcium Ion-Selective Electrode for Use in Flow Injection Potentiometry that Tolerates High Perchlorate Levels," Electroanalysis, Vol. 8, No. 4, 1996, pp. 391-395. doi:10.1002/elan.1140080417

[21] K. Suzuki, K. Watanabe, Y. Matsumoto, M. Kobayashi, S. Sato, D. Siswanta and H. Hisamoto, "Design and Synthesis of Calcium and Magnesium Ionophores Based on Double-Armed Diazacrown Ether Compounds and Their Application to an Ion Sensing Component for an Ion-Selective Electrode,” Analytical Chemistry, Vol. 67, No. 2, 1995, 324-334. doi:10.1021/ac00098a016

[22] W. E. Morf, K. Seiler, B. Rusterholz, W. Simon, "Design of a Novel Calcium-Selective Optode Membrane Based on Neutral Ionophores," Analytical Chemistry, Vol. 62, No. 7, 1990, pp. 738-742. doi:10.1021/ac00206a018

[23] U. Lange, N. V. Roznyatovskaya and V. M. Mirsky, "Conducting Polymers in Chemical Sensors and Arrays," Analytica Chimica Acta, Vol. 614, No. 1, 2008, pp. 1-26. doi:10.1016/j.aca.2008.02.068
[24] D. Goldstein and R. Stark-Mayer, "New Specific Test for Calcium”, Analytica Chimica Acta, Vol. 19, 1958, pp. 437-439. doi:10.1016/S0003-2670(00)88191-X

[25] J. M. Sunshine, C. M. Pieters and S. F. Pratt, "Deconvolution of Mineral Absorption Bands: An Improved Approach,” Journal of Geophysical Research, Vol. 95, No. B5, 1990, pp. 6955-6966. doi:10.1029/JB095iB05p06955

[26] M. Ahmad and R. Narayanaswamy, "Fibre Optic Reflectance Sensor for the Determination of Aluminium (III) in Aqueous Environment," Analytica Chimica Acta, Vol. 291, No. 3, 1994, pp. 255-260. doi:10.1016/0003-2670(94)80020-0

[27] S. H. Alabbas, D. C. Ashworth, B. Bezzaa, S. A. Momin and R. Narayanaswamy, "Factors Affecting the Response Time of an Optical-Fibre Reflectance $\mathrm{pH}$ Sensor," Sensors Actuators A, Vol. 51, No. 2, 1996, 129-134. doi:10.1016/0924-4247(95)01212-5

[28] H. Filik, M. M. Hayvali, E. Kiliç, R. Apak, D. Aksu, Z. Yanaz and T. Cengel, "Development of an Optical Fibre Reflectance Sensor for P-Aminophenol Detection Based on Immobilised Bis-8-hydroxyquinoline,” Talanta, Vol. 77, No. 1, 2008, pp. 103-109. doi:10.1016/j.talanta.2008.05.045

[29] H. Filik, D. Aksu, R. Apak, I. Sener and E. Kılıc, “An Optical Fibre Reflectance Sensor for $P$-aminophenol Determination Based on Tetrahydroxycalix[4]arene as Sensing Reagent," Sensors Actuators B, Vol. 136, No. 1-2, 2009, pp. 105-112. doi:10.1016/j.snb.2008.11.011

[30] I. Oehme and O. S. Wolfbeis, "Optical Sensors for Determination of Heavy Metal Ions,” Microchimica Acta, Vol. 126, No. 3, 1997, pp. 177-192. doi:10.1007/BF01242319

[31] N. A. Yusof and M. Ahmad, “A Flow Cell Optosensor for Lead Based on Immobilized Gallocynin in Chitosan Membrane," Talanta, Vol. 58, No. 3, 2002, pp. 459-466. doi:10.1016/S0039-9140(02)00308-9

[32] N. Mahendra, P. Gangaiya, S. Sotheeswaran and R. Narayanaswamy, "Investigation of a Fibre Optic Copper Sensor Based on Immobilised [alpha]-Benzoinoxime (cupron)," Sensors Actuators B, Vol. 90, No. 1-3, 2003, pp. 118-123. doi:10.1016/S0925-4005(03)00044-3

[33] A. A. Ensafi and M. Fouladgar, "Development of a Spectrophotometric Optode for the Determination of Hg (II) ," IEEE Sensors Journal, Vol. 8, No. 4, 2008, pp. 347-353. doi:10.1109/JSEN.2008.917482 